Article

\title{
Modelling of Autonomous Search and Rescue Missions by Interval-Valued Neutrosophic WASPAS Framework
}

\author{
Rokas Semenas and Romualdas Bausys * D \\ Department of Graphical Systems, Vilnius Gediminas Technical University, Sauletekio al. 11, LT-10223 Vilnius, \\ Lithuania; rokas.semenas@vgtu.lt \\ * Correspondence: romualdas.bausys@vgtu.lt
}

Received: 20 December 2019; Accepted: 9 January 2020; Published: 13 January 2020

check for updates

\begin{abstract}
The application of autonomous robots in search and rescue missions represents a complex task which requires a robot to make robust decisions in unknown and dangerous environments. However, imprecise robot movements and small measurement errors obtained by robot sensors can have an impact on the autonomous environment exploration quality, and therefore, should be addressed while designing search and rescue (SAR) robots. In this paper, a novel frontier evaluation strategy is proposed, that address technical, economic, social, and environmental factors of the sustainable environment exploration process, and a new extension of the weighted aggregated sum product assessment (WASPAS) method, modelled under interval-valued neutrosophic sets (IVNS), is introduced for autonomous mobile robots. The general-purpose Pioneer 3-AT robot platform is applied in simulated search and rescue missions, and the conducted experimental assessment shows the proposed method efficiency in commercial and public-type building exploration. By addressing the estimated measurement errors in the initial data obtained by the robot sensors, the proposed decision-making framework provides additional reliability for comparing and ranking candidate frontiers. The interval-valued multi-criteria decision-making method combined with the proposed frontier evaluation strategy enables the robot to exhaustively explore and map smaller SAR mission environments as well as ensure robot safety and efficient energy consumption in relatively larger public-type building environments.
\end{abstract}

Keywords: interval-valued neutrosophic sets; multi-criteria decision-making; WASPAS-IVNS; autonomous mobile robots; search and rescue

\section{Introduction}

Nowadays, autonomous robot systems, such as industrial robots [1], autonomous cars [2], social [3] and service robots [4], are increasingly applied to solve real-life problems, and therefore represent a constant object of discussion, not only from the technical, but also from social and ethical perspectives [5]. Progressively growing autonomous robots decision-making capabilities enable such systems to replace humans in labour-intense and dangerous tasks, such as infrastructure maintenance and inspection [6,7], or environment exploration and data gathering tasks, such as search and rescue missions $[8,9]$.

In general, search and rescue missions are complex tasks in which autonomous robots must safely explore the disaster sites and provide rescue teams with important information, such as victim locations and status, environmental conditions, and the locations of dangerous objects $[8,10,11]$. While designing robots capable of addressing these tasks, several strategies can be taken into consideration. Robot physical structure can be modified to address specific navigation requirements (e.g., opening 
doors [12]), or robot software components can be improved, namely, the environment perception module, the self-localisation module, the motion control module, and the decision-making module [13]. Generally, the same type of software components can be transferred and applied between different robots. Therefore, this research is aimed at improving the decision-making module, which is responsible for sensor-obtained data interpretation and conversion to expected environment exploration behaviour in search and rescue missions.

Considering the lasting effects [14] that autonomous robots have when applied in search and rescue missions, the decision-making module is required to make efficient decisions by incorporating variating mission criteria into consideration. This problem is modelled by taking into account two different viewpoints: what criteria are applied for modelling effective autonomous environment exploration module, and what strategy is applied for the decision-making process. Hence, in this paper a novel frontier evaluation strategy is proposed, that addresses the technical, economic, social and environmental factors of autonomous search and rescue missions. Also, a new extension of the weighted aggregated sum product assessment (WASPAS) multi-criteria decision-making method modelled under the interval-valued neutrosophic sets (IVNS), namely WASPAS-IVNS, is proposed for candidate frontier evaluation and selection in autonomous search and rescue missions.

This paper is structured in the following manner. The review of environment exploration methodology is presented in Section 2. Section 3 introduces a new WASPAS-IVNS framework which is the core part of robot decision-making module. Also, in this section, criteria selection and calculation process, robot architecture, and the proposed search and rescue strategy are explained in detail. The experimental evaluation methodology, results, and discussion are presented in Section 4. Conclusions and future work are presented in Section 5.

\section{Autonomous Environment Exploration in SAR Mission}

\subsection{Environment Exploration Methodology}

Environmental exploration by autonomous mobile robots is a process through which an unknown environment is analysed and mapped by visiting all available areas. Many recent studies were aimed at improving this process $[15,16]$, including research in extreme environments $[11,17]$ and planetary exploration $[18,19]$. Although many different strategies have been introduced to address unknown environment exploration problems, a popular and easy-to-implement basis for autonomous mobile robot testing remains the frontier-based environment exploration method, originally proposed by Yamauchi [20]. This strategy describes frontiers as a boundary between the known and unknown portions of the environment. By continuously directing the robot to the previously unvisited frontiers, an exhaustive environment analysis can be achieved. Several papers address and implement this strategy. For example, exploration planning strategy for large-scale unknown environments was proposed in [21], and the frontier point selection strategy, based on the frontier point optimisation and multistep path planning was proposed in [22].

In autonomous SAR missions, robots are expected to make robust decisions by addressing a number of conflicting requirements set by the stakeholders. Hence, the original frontier-based environment exploration approach, which evaluates a single criterion (distance to the frontier), is not effective in this context. A more effective approach to this problem is to compose a set of criteria and evaluate each candidate frontier accordingly. Considering search and rescue missions, autonomous robots are deployed as data-collecting tools that provide information to the rescue teams [9]. In this situation firefighting teams, medic teams, robot providers, and victims can be considered as stakeholders with different preferences [14]. Naturally, victims hope to be saved, and medic teams prefer robots to detect, reach, and constantly monitor the state of injured or trapped victims. On the other hand, firefighting teams can prefer robots to scan the disaster site and provide data about the general environment layout and dangerous objects in the vicinity to ensure the safety of rescue personnel. Finally, robot providers would prefer to keep their property economically viable and safe (e.g., to optimise energy 
usage and avoid direct environmental damage to the robot to reduce its maintenance costs). All these preferences can be denoted as environmental, technical, social, and economic factors that robots' decision-making module must address during the environment exploration process. By analysing and balancing contradicting stakeholder preferences, a set of criteria can be composed and applied to evaluate candidate frontiers [23].

\subsection{Candidate Frontier Evaluation Methodology}

Considering the iterative frontier-based environment exploration approach, and a heavily criteria-based nature of the problem, we argue that multi-criteria decision-making (MCDM) frameworks can be applied to improve robots decision-making module.

MCDM frameworks are robust tools that can be applied to model and solve real-world problems, such as various selection problems, performance evaluations, and safety assessments [24]. For example, MCDM methods for lead-zinc flotation circuit selection problem, and location selection problem for waste incineration plants were proposed in $[25,26]$. MCDM frameworks were also successfully applied to the house shape evaluation problem by Juodagalviene et al. [27]. Stojić et al. [28] proposed a methodology for supplier selection for manufacturing chains, and more recently an MCDM-based safety evaluation methodology for urban parks was introduced in [29]. Several survey papers also address MCDM framework applications in sustainable development [30,31].

Considering the research field of robotics and autonomous robots, MCDM frameworks have also been the focus of some decision-making related studies, for example, selection method of automatically guided vehicles for warehouse automation was proposed in [32]. Ghorabaee [33] proposed a method for industrial robot selection. A similar industrial robot selection problem has also been addressed in [34]. However, these papers focus on the robot selection problem and not the actual environment exploration by autonomous mobile robots. Autonomous search and rescue missions by MCDM-driven decision-making module has first been introduced by Amigoni and Basilico [35]. Following this research, a PROMETHEE II method was proposed in [36] to improve the robot decision-making ability, and a recent study by Bausys et al. [23] introduced WASPAS extension by single-valued neutrosophic sets, directed to incorporate sustainability principles in autonomous environment exploration by mobile robots.

Although these strategies show efficiency in the iterative decision-making process, the MCDM application capabilities in autonomous search and rescue missions are yet to be exhaustively studied. Considering the discussed MCDM approaches, the decision-making module evaluates criteria based on the raw data obtained by the robot sensors, without the evaluation of measurement errors. However, in real-world scenarios, every sensor can produce small measurement errors which can be addressed by the autonomous mobile robots decision-making module to improve the exploration process. This is the most powerful motivation to extend the MCDM frameworks and introduce a new decision-making strategy that takes advantage of interval-valued neutrosophic sets and reduces the impact of measurement errors in autonomous search and rescue missions.

\section{Methods}

\subsection{Autonomous Mobile Robot Architecture}

The proposed MCDM approach is applied to extend the decision-making module of the general-purpose four-wheel mobile ground robot Pioneer 3-AT [37]. This platform is chosen due to its applicability in search and rescue missions [35,38]. The robot movement and environment perception functions, namely the control of robot movement and rotation velocity, odometry information publishing, interpretation of sensor data, construction of two-dimensional environment map, and path planning, are managed by the robot operating system (ROS) [39]. However, the robot decision-making module is controlled explicitly by applying the proposed MCDM framework. 
In this research, an autonomous search and rescue mission is modelled and simulated in Gazebo software [40]. Hence, the software-provided pre-made Pioneer 3-AT robot is imported into the simulation and equipped with a virtual Hokuyo laser range scanner sensor. This sensor has a $260^{\circ}$ line of sight and is the main perception device used by the robot to detect physical structures and obstacles in an exploration environment. Considering that victim and dangerous object recognition poses a set of problems that are out of the scope of this research, it is assumed that robot has sensing capabilities to identify these problem-related objects of interest (OOIs) with perfect accuracy.

To track its current position in space, and the position of detected OOIs, the autonomous robot builds a two-dimensional, $0.1 \mathrm{~m}$ cell-resolution grid map [41], based on the data obtained by the laser range scanner sensor. In this environment representation model, the exploration area is divided into square cells, where each cell corresponds to the real-world geometrical space and contains the value of cells' occupancy probability. These probability values are in the range of $[0,100]$, where 0 is considered as a free cell and contains no visible obstacles, and the value of 100 indicates that corresponding area is occupied. In this model, the probability value of -1 indicates, that the corresponding area has not been perceived, and the cell value is unknown.

In the modelled search and rescue mission, the Pioneer 3-AT robot applies the iterative frontier selection strategy, which is presented in Figure 1. At the start of the first iteration, no initial information about the environment and the locations of task-related OOIs are available to the robot. Therefore, for its' first move, the robot is programmed to turn around by $360^{\circ}$ and scan the surrounding area. Then, environmental data obtained by the laser range scanner sensor are mapped on a two-dimensional grid by applying the previously described grid map building methodology. When the map is updated, robot estimates its position on the constructed grid by applying ROS-provided self-localisation algorithm [41] and detects all groups of free cells that are bordering the unknown grid map cells. For each of these cell groups (frontiers), the centre point coordinate is calculated and added to the list of available candidate frontiers. Then, the robot activates the decision-making module and each candidate frontier is evaluated by applying the criteria set, presented in Table 1, and the proposed interval-valued neutrosophic MCDM framework. The highest-ranked candidate frontier is then selected by the decision-making module. Finally, the robot moves to the selected frontier and updates the partial grid map information with newly obtained data. This data acquisition, evaluation, and frontier selection process is repeated by the decision-making module until one of two conditions are met: the given time limit has passed or there are no candidate frontiers left.

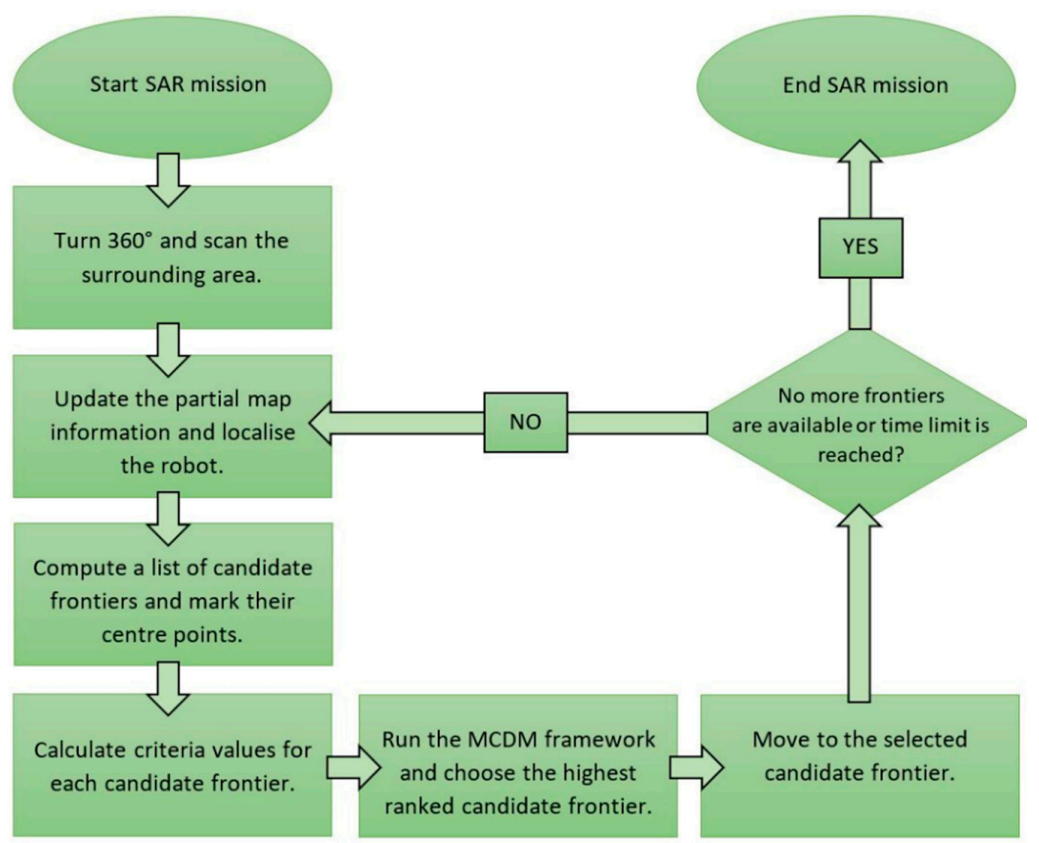

Figure 1. Iterative environment exploration strategy applied by the autonomous robot. 
Table 1. The proposed criteria set for search and rescue mission.

\begin{tabular}{cccccc}
\hline Type & Denotation & Name & Min/Max & $\begin{array}{c}\text { Measurement } \\
\text { Units }\end{array}$ & $\begin{array}{c}\text { Estimated } \\
\text { Measurement } \\
\text { Error }\end{array}$ \\
\hline Technical & $C_{1}$ & $\begin{array}{c}\text { Distance to the } \\
\text { control station }\end{array}$ & Min & $\mathrm{m}$ & $\pm 1 \mathrm{~m}$ \\
\hline Technical & $C_{2}$ & $\begin{array}{c}\text { The estimated } \\
\text { amount of new } \\
\text { information }\end{array}$ & Max & $\mathrm{m}$ & $\pm 0.1 \mathrm{~m}$ \\
\hline Social & $C_{3}$ & $\begin{array}{c}\text { Estimated victim } \\
\text { danger }\end{array}$ & Max & $\begin{array}{c}\text { Danger points } \\
(\mathrm{dp})\end{array}$ & $\pm 0.2 \mathrm{p}$ \\
\hline Economic & $C_{4}$ & $\begin{array}{c}\text { Estimated damage } \\
\text { to the robot }\end{array}$ & Min & $\begin{array}{c}\text { Penalty points } \\
(\mathrm{pp})\end{array}$ & $\pm 0.2 \mathrm{p}$ \\
\hline Environmental & $C_{5}$ & $\begin{array}{c}\text { Estimated energy } \\
\text { consumption }\end{array}$ & Min & $\mathrm{s}$ & $\pm 10 \mathrm{~s}$ \\
\hline Technical & $C_{6}$ & $\begin{array}{c}\text { Distance from the } \\
\text { robot to the } \\
\text { candidate frontier }\end{array}$ & Min & $\mathrm{m}$ & $\pm 1 \mathrm{~m}$ \\
\hline
\end{tabular}

Since frontier selection strategy is extended by applying MCDM methodology, next subchapters are dedicated to introducing this MCDM problem formulation, criteria evaluation, and weight selection methodology, as well as a detailed presentation of the proposed interval-valued neutrosophic WASPAS framework.

\subsection{Problem Formulation}

In general, each individual candidate frontier, with a centre point $a_{i}(x, y)$ in an iteratively-obtained set of $m$ candidate frontiers $A=\left(a_{1}, \ldots, a_{m}\right)$ can be evaluated by applying a set of $n$ criteria, denoted by $C=\left(c_{1}, \ldots, c_{n}\right)$. Each criterion in $C$, has an assigned weight value $w_{j}$, indicating its relative importance to other criteria. By assigning $a_{i}(x, y)$ a vector of weighted criteria $C\left(a_{i}\right)=\left(c_{1}\left(a_{i}\right), c_{2}\left(a_{i}\right), \ldots, c_{n}\left(a_{i}\right)\right)$, and applying MCDM framework, global utility value $Q\left(a_{i}\right)$ of a candidate frontier can be measured and compared to other candidate values. Considering the proposed environment exploration strategy, the robot is directed to the candidate frontier with the highest $Q\left(a_{i}\right)$.

\subsection{Criteria for Frontier Evaluation in Autonomous Search and Rescue Mission}

Criteria selection for autonomous search and rescue mission is essential to design a balanced strategy that addresses different requirements, set by the stakeholders. Considering the analysis of autonomous environment exploration strategies, robot decision-making modules are commonly driven by spatial-information-based criteria [36], such as distances between the robot and other objects. However, some search and rescue mission requirements, namely economic and social criteria, currently have lack evidence of an established and published globally-recognised evaluation methodology, suitable for frontier selection in search and rescue missions. Therefore, in the context of this research, we propose to estimate such criteria values by analysing the spatial information.

A total of six criteria are proposed to design an effective decision-making strategy and to address technical, social, environmental, and economic requirements of autonomous search and rescue missions. The subset of criteria, namely $c_{1}$, the distance to the control station, $c_{2}$, the estimated amount of new information that would be gained after reaching the candidate location, $c_{5}$, the estimated energy needed to reach the candidate location, and $c_{6}$, the distance from the robot to candidate frontier location, are traditionally applied in modelling SAR missions $[23,35,36]$. In the context of this research, we also introduce two criteria, denoted as $c_{3}$, the estimated danger to victims, and $c_{4}$, the estimated danger to the robot, to address social and economic aspects of search and rescue missions. The complete criteria set is presented in Table 1 . 
Distance to the control station is a technical criterion that essentially defines if a robot can transmit the obtained information after reaching the candidate frontier $[35,36]$. If the control station has a constant position $p_{s}(x, y)$, the distance to the candidate frontier denoted as $a_{i}(x, y)$ in $A$ can be measured as a Euclidean distance. By minimising this criterion, the robot can be directed to the nearest candidate frontiers to conduct an exhaustive exploration of the nearby vicinity. On the contrary, maximising this criterion adjusts the robot behaviour to prioritise further located frontiers to conduct fast-paced environment coverage. Considering the operational parameters set to the robot path planning algorithm, the estimated measurement error for this criterion is set to $\pm 1 \mathrm{~m}$.

Similarly, the Euclidean distance from the current robot position $p_{c u r}(x, y)$ to the candidate frontier $a_{i}(x, y)$ can be measured and minimised to avoid backtracking behaviour. This technical criterion should ensure that most of the frontiers around the robot would be visited before returning to the frontiers that are closer to the control station.

The last technical criterion in the proposed criteria set, namely, the estimated amount of new information that is expected to be gained by visiting the candidate frontier $a_{i}(x, y)$ is considered to be equal to the length of the frontier. In the context of this research, the autonomous robot applies an ROS-provided Gmapping module [41] to map the unknown environment. In this case, a grid representation is applied, where each cell contains occupancy information. By detecting free cell chains that are neighbouring unknown cells, robot decision-making module can measure candidate frontier length and direct the robot to frontiers that are estimated to provide more information. Considering the resolution of the reconstructed grid map, the estimated measurement error for this criterion is set to $\pm 0.1 \mathrm{~m}$.

Estimated energy that would be consumed by reaching the candidate frontier represents the movement cost and address the environmental factor of search and rescue mission. The decision-making module estimates the criterion value by measuring the time $t_{a_{i}}$ needed to reach the candidate frontier $a_{i}(x, y)$. To estimate this criterion value, an autonomous robot computes a set of paths $R=\left(r_{1}, r_{2}, \ldots, r_{k}\right)$ for each candidate frontier $a_{i}(x, y)$ in set $A$, and each path $r=\left(w p_{1}, w p_{2}, \ldots, w p_{m}\right)$ is constructed from a set of $m$ waypoints $w p$. In $r$, starting from the current robot position $p_{c u r}=w p_{1}$ to the candidate frontier $a_{i}(x, y)=w p_{m}$, two connecting waypoints $w p_{i}$ and $w p_{i+1}$ create a path segment. Therefore, the distance between two waypoints can be denoted as $d\left(w p_{i}, w p_{i+1}\right)$ and the corner between two lines can be expressed as $\alpha\left(w p_{i}, w p_{i+1}, w p_{i+2}\right)$. The criterion value can be measured by:

$$
t_{a_{i}}=\frac{\sum_{i=1}^{m} d\left(w p_{i}, w p_{i+1}\right)}{v_{m}}+\frac{\sum_{i=1}^{m} \alpha\left(w p_{i}, w p_{i+1}, w p_{i+2}\right)}{v_{r}}
$$

where $v_{m}=0.1 \mathrm{~m} / \mathrm{s}$ is the minimum robot movement velocity, and $v_{r}=0.1 \%$ is the minimum robot rotation velocity. Naturally, the decision-making module should minimise the criterion to prolong the robot operation time. Considering the operational parameters set to the robot path planning algorithm, the estimated measurement error for this criterion is set to $\pm 10 \mathrm{~s}$.

The estimated damage for following the planned path is an important economic criterion which addresses the robot safety in search and rescue missions. During these missions, several events may occur that can directly affect the autonomous environment exploration process (e.g., some parts of the building can collapse, blocking the previously traversable path or damaging the robot). High radiation, open fire sources, and other dangerous obstacles can also affect the robot, making it unable to continue the mission [9]. In the context of this research, such objects are treated as dangerous objects of interest (OOIs) that are randomly distributed through the search and rescue environment. The estimated danger to the robot is calculated by introducing a penalty point system. The decision-making module calculates Euclidean distances $d_{d}$ from each waypoint $w p$ in a path $r$ to all known dangerous OOIs in $O_{d}=\left(O O I_{d_{1}}, O O I_{d_{2}}, \ldots, O O I_{d_{n}}\right)$. The penalty points $p p$ are calculated by linearly increasing their value from 0 to 3 , depending on the distance between the $O O I_{i}$ and each $w p$ in $r$. For example, if the distance between $w p_{i}$ and $O O I_{i}$ is greater than $3 \mathrm{~m}$, the robot is safe and receives no penalty points. However, if the distance between $w p_{i}$ and $O O I_{i}$ is $2 \mathrm{~m}$, the robot receives one penalty point. 
Subsequently, if the distance is $0.5 \mathrm{~m}$, robot receives 2.5 penalty points. Considering the resolution of the reconstructed grid map, the estimated measurement errors for point-based criteria are set to $\pm 0.2 \mathrm{p}$, and the criterion value $p p_{i}$ is estimated by the sum of all penalty points for each path by the following equation:

$$
\begin{gathered}
p p_{i}=\sum_{j=1}^{n} \sum_{i=1}^{m} d_{d}\left(w p_{i}, \mathrm{OOI}_{d_{j}}\right) \\
d_{d}\left(w p_{i}, \mathrm{OOI}_{d_{j}}\right)= \begin{cases}3-d\left(w p_{i}, \mathrm{O}_{d_{j}}\right) ; & \text { if } d\left(w p_{i}, \mathrm{OOI}_{d_{j}}\right)<3 \\
& 0 \text { otherwise }\end{cases}
\end{gathered}
$$

Finally, the estimated danger to the victim is a social criterion, designed to direct the robot closer to an injured person and collect more data about them and their environment. First, the decision-making module evaluates the Euclidean distance $d_{v}$ from each $w p$ in the planned path $r$ to all visible victims $O_{v}=\left(O O I_{v 1}, O O I_{v 2}, \ldots, O O I_{v n}\right)$. If $d_{v}<6 \mathrm{~m}$, the danger posed to the victim by nearby dangerous OOIs in $\mathrm{O}_{d}=\left(\mathrm{OOI}_{d_{1}}, \mathrm{OOI}_{d_{2}}, \ldots, O O I_{d_{n}}\right)$ can be estimated by applying the previously described linear point-based methodology. However, in this case, the area-of-effect zones for dangerous OOIs are increased to $6 \mathrm{~m}$ and the sum of danger points, denoted by $d p_{i}$, can be estimated by the following equation:

$$
\begin{aligned}
& d p_{i}=\sum_{j=1}^{n} \sum_{i=1}^{m} d_{v}\left(\mathrm{OOI}_{v i}, \mathrm{OOI}_{d_{j}}\right) \\
& d_{v}\left(O O I_{v_{i}}, O O I_{d_{j}}\right)= \begin{cases}6-d\left(O O I_{v_{i}}, O O I_{d_{j}}\right) ; & \text { if } d\left(O O I_{v_{i}}, O O I_{d_{j}}\right)<6 \\
& \text { and } d\left(w p_{i}, O O I_{v_{i}}\right)<6 \\
& 0 \text { otherwise }\end{cases}
\end{aligned}
$$

By utilising technical, environmental, economic, and social criteria, the robot decision-making module can make more precise decisions in search and rescue missions. However, criteria weights need to be adjusted to ensure the balanced and efficient environment exploration process.

\subsection{Weight Selection}

To ensure the efficiency of the proposed decision-making strategy, an expert group was formed to evaluate the applicability of the proposed criteria set, and to determine weights for each criterion. A total of seven experts working in the field of autonomous robots and decision-making systems participated in criteria ranking and weighting process. To convert variating expert opinions into a well-formed weight set, a stepwise weight assessment ratio analysis (SWARA) [42] is applied. The general weight calculation process by SWARA method can be described as follows:

1. The criteria set directed to addressing common task requirements are composed and evaluated by the experts.

2. Next, experts sort the criteria by their importance in descending order.

3. Then, pairwise comparison is conducted to estimate criteria relative importance $s_{j \leftrightarrow j+1}$, and an average criteria importance values $s_{j}$ are calculated for each criterion.

4. The coefficients of the comparative importance indicators are assessed by $k_{j}=s_{j}+1$.

5. The intermediate weights are calculated for each criterion by $q_{j}=\frac{q_{j-1}}{k_{j}}$.

6. Finally, normalised criteria weight values are calculated by $w_{j}=\frac{q_{j}}{\sum_{j=1}^{n} q_{j}}$.

By analysing the autonomous unknown environment exploration problem, the experts have agreed on the criteria importance order, presented in Table 1. The criteria weight calculation process and results obtained by the SWARA method are provided in Tables 2 and 3. 
Table 2. Pairwise comparison of criteria relative importance.

\begin{tabular}{cccccc}
\hline \multirow{2}{*}{ Expert } & \multicolumn{5}{c}{ Pairwise Comparison of Criteria Relative Importance } \\
\cline { 2 - 6 } & $c_{1 \leftrightarrow 2}$ & $c_{2 \leftrightarrow 3}$ & $c_{3 \leftrightarrow 4}$ & $c_{4 \leftrightarrow 5}$ & $c_{5 \leftrightarrow 6}$ \\
\hline 1 & 0.25 & 0.20 & 0.40 & 0.30 & 0.05 \\
2 & 0.20 & 0.10 & 0.50 & 0.50 & 0.20 \\
3 & 0.30 & 0.30 & 0.20 & 0.80 & 0.25 \\
4 & 0.25 & 0.20 & 0.20 & 0.70 & 0.20 \\
5 & 0.40 & 0.25 & 0.35 & 0.40 & 0.10 \\
6 & 0.10 & 0.15 & 0.10 & 0.10 & 0.10 \\
7 & 0.20 & 0.00 & 0.30 & 0.40 & 0.20 \\
\hline
\end{tabular}

Table 3. Criteria weight determination for autonomous search and rescue mission.

\begin{tabular}{ccccc}
\hline Criterion & $\begin{array}{c}\text { Average Value of } \\
\text { Comparative } \\
\text { Importance Indicators, } \\
s_{j \leftrightarrow j+1}\end{array}$ & $\begin{array}{c}\text { Coefficients of } \\
\text { Comparative } \\
\text { Importance Indicators, } \\
\boldsymbol{k}_{j}\end{array}$ & $\begin{array}{c}\text { Recalculated } \\
\text { Indicator Weights, } \\
\boldsymbol{q}_{j}\end{array}$ & $\begin{array}{c}\text { Final Weights, } \\
\boldsymbol{w}_{j}\end{array}$ \\
\hline$c_{1}$ & - & 1.000 & 1.000 & 0.270 \\
$c_{2}$ & 0.243 & 1.243 & 0.805 & 0.217 \\
$c_{3}$ & 0.171 & 1.171 & 0.687 & 0.186 \\
$c_{4}$ & 0.293 & 1.293 & 0.531 & 0.143 \\
$c_{5}$ & 0.457 & 1.457 & 0.365 & 0.099 \\
$c_{6}$ & 0.157 & 1.157 & 0.315 & 0.085 \\
\hline
\end{tabular}

\subsection{WASPAS-IVNS Framework}

The original weighted aggregated sum product assessment method was first introduced in [43]. Since then, the framework has been extended several times [44] to better address uncertainties in initial data. As a product of such development, a recent WASPAS extension by single-valued neutrosophic sets [45], namely WASPAS-SVNS, was introduced in [25]. This method essentially enables the robot designer to model decision-related information by truth, falsity, and indeterminacy functions and has already been applied in an autonomous environment exploration task [23]. The WASPAS framework is constructed from two objectives which provide additional reliability in the decision-making process. Also, the WASPAS method requires very few computational resources, which is especially relevant for real-time applications. However, to address the problem of the small errors produced by imprecise robot movements and imperfect sensor readings, we propose a new formulation of WASPAS method, modelled under interval-valued neutrosophic set environment, namely WASPAS-IVNS. The general properties of the interval-valued neutrosophic set (IVNS) [46], and the proposed WASPAS-IVNS framework are presented as follows.

If a set of criteria modelled under the interval-valued neutrosophic environment is considered as a domain of problem-related objects $X$, and $x \in X$ is a value of the single criterion, an interval-valued neutrosophic set $N \subset X$ can be denoted by a general form of:

$$
N=\left\{\left\langle x, T_{N}(x), I_{N}(x), F_{N}(x)\right\rangle: x \in X\right\}
$$

where $T_{N}(x): X \rightarrow[0,1], I_{N}(x): X \rightarrow[0,1], F_{N}(x): X \rightarrow[0,1]$, and $0 \leq T_{N}(x)+I_{N}(x)+F_{N}(x) \leq 3$ for all $x \in X$. The three membership degree functions define $N$ : the truth-membership degree function $T_{N}(x)$, the indeterminacy-membership degree function $I_{N}(x)$, and the falsity-membership degree function $F_{N}(x)$. These functions are described by subsets of $T_{N}(x)=\left[\inf T_{N}(x), \sup T_{N}(x)\right] \subseteq[0,1]$, $I_{N}(x)=\left[\inf I_{N}(x), \sup I_{N}(x)\right] \subseteq[0,1], F_{N}(x)=\left[\inf F_{N}(x), \sup F_{N}(x)\right] \subseteq[0,1]$ with the sum condition of $0 \leq \sup T_{N}(x)+\sup I_{N}(x)+\sup F_{N}(x) \leq 3$. 
Like all multi-criteria decision-making methods, the WASPAS-IVNS approach begins with a construction of the decision matrix $Y$. The single matrix object $y_{i j} \in Y, i=1, \ldots, n$ and $j=1, \ldots, m$ is modelled under the interval-valued neutrosophic environment and corresponds to the $i^{\text {th }}$ criteria of $j^{\text {th }}$ alternative (in this research, a candidate frontier). This decision matrix can be expressed as:

$$
Y=\left[\begin{array}{ccc}
y_{11} & \cdots & y_{1 m} \\
\vdots & \ddots & \vdots \\
y_{n 1} & \cdots & y_{n m}
\end{array}\right]
$$

Next, decision matrix elements are normalised by applying the following normalisation function:

$$
\inf y_{i j}^{*}=\frac{\inf y_{i j}}{\max _{i} \sqrt{m}}, \sup y_{i j}^{*}=\frac{\sup y_{i j}}{\max _{i} y_{i j} \sqrt{m}}
$$

After element normalisation, the neutrosophication step is performed, and the initially crisp values of the decision matrix are transformed into interval-valued neutrosophic numbers. For this conversion, modification rates presented in [25] are applied.

After this step, the first objective of WASPAS-IVNS framework, which is based on the sum of the total relative importance of the alternative $j$, is calculated by the following equation:

$$
Q_{j}^{(1)}=\sum_{i=1}^{L_{\max }}\left(y_{n}^{*}\right)_{i j} \cdot w_{i}+\left(\sum_{i=1}^{L_{\min }}\left(y_{n}^{*}\right)_{i j} \cdot w_{i}\right)^{c}
$$

where $j$ is the alternative, and $\left(y_{n}^{*}\right)_{i j}$ are interval-valued neutrosophic members with $w_{i}$ weight. $L_{\max }$ corresponds to criteria set members that are maximised, and $L_{\min }$ corresponds to criteria set members that are minimised.

The second objective of WASPAS-IVNS framework, which is based on the product total relative importance of alternative $j$, can be calculated by the following equation:

$$
Q_{j}^{(2)}=\prod_{i=1}^{L_{\max }}\left(y_{n}^{*}\right)_{i j}{ }^{w_{i}} \cdot\left(\prod_{i=1}^{L_{\min }}\left(y_{n}^{*}\right)_{i j}{ }^{w_{i}}\right)^{c}
$$

Members of this function share their definitions with those provided for Equation (7). Finally, the value of the joint generalised criteria is determined by:

$$
Q_{j}=0.5 Q_{j}^{(1)}+0.5 Q_{j}^{(2)}
$$

To complete the WASPAS-IVNS objectives, the following interval neutrosophic algebra operations should be applied. The multiplication of interval-valued neutrosophic number $\left(y_{n}^{*}\right)=$ $\left\langle\left[\inf t_{n}, \sup t_{n}\right],\left[\inf i_{n}, \sup i_{n}\right],\left[\inf f_{n}, \sup f_{n}\right]\right\rangle$ and a positive real number $\lambda$ can be defined by Equation (10), and the complementary neutrosophic number component can be defined by Equation (11). The summation of two IVNNs $\left(y_{n 1}^{*}\right)=\left\langle\left[\inf t_{n 1}, \sup t_{n 1}\right],\left[\inf i_{n 1}, \sup i_{n 1}\right],\left[\inf f_{n 1}, \sup f_{n 1}\right]\right\rangle$ and $\left(y_{n 2}^{*}\right)=\left\langle\left[\inf t_{n 2}, \sup t_{n 2}\right],\left[\inf i_{n 2}\right.\right.$, sup $\left.\left.i_{n 2}\right],\left[\inf f_{n 2,}, \sup f_{n 2}\right]\right\rangle$ can be calculated by applying Equation (12). The power function of an interval-valued neutrosophic number and a positive real number $\lambda$, required by the second WASPAS-IVNS objective, is defined by Equation (13). Finally, the multiplication result of two IVNNs $\left(y_{n 1}^{*}\right)=\left\langle\left[\inf t_{n 1}, \sup t_{n 1}\right],\left[\inf i_{n 1}, \sup i_{n 1}\right],\left[\inf f_{n 1}, \sup f_{n 1}\right]\right\rangle$ and $\left(y_{n 2}^{*}\right)=\left\langle\left[\inf t_{n 2}, \sup t_{n 2}\right],\left[\inf i_{n 2}\right.\right.$, sup $\left.i_{n 2}\right],\left[\inf f_{n 2}\right.$, sup $\left.\left.f_{n 2}\right]\right\rangle$ can be calculated by applying the Equation (14): 


$$
\begin{aligned}
& \lambda\left(y_{n}^{*}\right)=\left\langle\left[ 1-\left(1-\inf t_{n}\right)^{\lambda}, 1\right.\right. \\
& \left.\left.-\left(1-\sup t_{n}\right)^{\lambda}\right],\left[\left(\inf i_{n}\right)^{\lambda},\left(\sup i_{n}\right)^{\lambda}\right],\left[\left(\inf f_{n}\right)^{\lambda},\left(\inf f_{n}\right)^{\lambda}\right]\right\rangle \\
& \left(y_{n}^{*}\right)^{c}=\left\langle\left[\inf f_{n}, \sup f_{n}\right],\left[1-\sup i_{n}, 1-\inf i_{n}\right],\left[\inf t_{n}, \sup t_{n}\right]\right\rangle \\
& \left(y_{n 1}^{*}\right)+\left(y_{n 2}^{*}\right)=\left\langle\begin{array}{l}
\left(\begin{array}{l}
\left(\inf t_{n 1}+\inf t_{n 2}-\inf t_{n 1} \cdot \inf t_{n 2}\right), \\
\left(\sup t_{n 1}+\sup t_{n 2}-\sup t_{n 1} \cdot \sup t_{n 2}\right)
\end{array}\right], \\
{\left[\begin{array}{cc}
\left(\inf i_{n 1} \cdot \inf i_{n 2}\right), & \left(\sup i_{n 1} \cdot \sup i_{n 2}\right)
\end{array}\right],}
\end{array}\right\rangle \\
& {\left[\left(\inf f_{n 1} \cdot \inf f_{n 2}\right),\left(\sup f_{n 1} \cdot \sup f_{n 2}\right)\right]} \\
& \left(y_{n}^{*}\right)^{\lambda}=\left\langle\begin{array}{c}
{\left[\left(\inf t_{n}\right)^{\lambda},\left(\sup t_{n}\right)^{\lambda}\right],} \\
{\left[1-\left(1-\sup i_{n}\right)^{\lambda}, 1-\left(1-\inf i_{n}\right)^{\lambda}\right],} \\
{\left[1-\left(1-\inf f_{n}\right)^{\lambda}, 1-\left(1-\sup f_{n}\right)^{\lambda}\right]}
\end{array}\right\rangle \\
& \text { [(inf } \left.\left.t_{n 1} \cdot \inf t_{n 2}\right),\left(\sup t_{n 1} \cdot \sup t_{n 2}\right)\right] \text {, } \\
& \left(y_{n 1}^{*}\right) \cdot\left(y_{n 2}^{*}\right)=\left\langle\begin{array}{l}
{\left[\begin{array}{l}
\left(\inf i_{n 1}+\inf i_{i 2}-\inf i_{n 1} \cdot \inf i_{n 2}\right), \\
\left(\sup i_{n 1}+\sup i_{n 2}-\sup i_{n 1} \cdot \sup i_{n 2}\right)
\end{array}\right],} \\
{\left[\begin{array}{l}
\left(\inf f_{n 1}+\inf f_{n 2}-\inf f_{n 2} \cdot \inf f_{n 2}\right), \\
\left(\sup f_{n 1}+\sup f_{n 2}-\sup f_{n 1} \cdot \sup f_{n 2}\right)
\end{array}\right]}
\end{array}\right\rangle
\end{aligned}
$$

To determine and select the highest-ranked candidate frontier, the obtained values can be compared by applying the interval-valued neutrosophic number comparison functions, namely, score function, denoted by $s\left(Q_{1}\right)$, accuracy function, denoted by $a\left(Q_{1}\right)$, and certainty function, denoted by $c\left(Q_{1}\right)$. These functions can be expressed by the following equations:

$$
\begin{gathered}
s\left(Q_{1}\right)=\left[\begin{array}{c}
\inf t_{n 1}+1-\sup i_{n 1}+1-\sup f_{n 1}, \\
\sup t_{n 1}+1-\inf i_{n 1}+1-\inf f_{n 1}
\end{array}\right] \\
a\left(Q_{1}\right)=\left[\begin{array}{l}
\min \left\{\inf t_{n 1}-\inf f_{n 1}, \sup t_{n 1}-\sup f_{n 1}\right\}, \\
\max \left\{\inf t_{n 1}-\inf f_{n 1}, \sup t_{n 1}-\sup f_{n 1}\right\}
\end{array}\right] \\
c\left(Q_{1}\right)=\left[\inf t_{n 1}, \sup t_{n 1}\right]
\end{gathered}
$$

The comparison of two SVNNs by score, accuracy and certainty functions can be completed in the following:

1. If $p\left(s\left(Q_{1}\right) \geq s\left(Q_{2}\right)\right)>0.5$, then $Q_{1}>Q_{2}$, or $Q_{1}$ is superior to $Q_{2}$.

2. If $p\left(s\left(Q_{1}\right) \geq s\left(Q_{2}\right)\right)=0.5$ and $p\left(a\left(Q_{1}\right) \geq a\left(Q_{2}\right)\right)>0.5$, then $Q_{1}>Q_{2}$, or $Q_{1}$ is superior to $Q_{2}$.

3. If $p\left(s\left(Q_{1}\right) \geq s\left(Q_{2}\right)\right)=0.5, p\left(a\left(Q_{1}\right) \geq a\left(Q_{2}\right)\right)=0.5$ and $p\left(c\left(Q_{1}\right) \geq c\left(Q_{2}\right)\right)>0.5$, then $Q_{1}>Q_{2}$, or $Q_{1}$ is superior to $Q_{2}$.

4. If $p\left(s\left(Q_{1}\right) \geq s\left(Q_{2}\right)\right)=0.5, p\left(a\left(Q_{1}\right) \geq a\left(Q_{2}\right)\right)=0.5$ and $p\left(c\left(Q_{1}\right) \geq c\left(Q_{2}\right)\right)=0.5$, then $Q_{1}$ is equal to $Q_{2}$, or $Q_{1} \sim Q_{2}$.

The degree of the possibility of the score function is determined by the following equation:

$$
\begin{aligned}
& p\left(s\left(Q_{1}\right) \geq s\left(Q_{2}\right)\right) \\
& =\max \left\{1-\max \left(\frac{\sup \left(s\left(Q_{2}\right)\right)-\inf \left(s\left(Q_{1}\right)\right)}{\left(\sup \left(s\left(Q_{1}\right)\right)-\inf \left(s\left(Q_{1}\right)\right)\right)+\left(\sup \left(s\left(Q_{2}\right)\right)-\inf \left(s\left(Q_{2}\right)\right)\right)}, 0\right), 0\right\}
\end{aligned}
$$

The degrees of the possibility for the accuracy and certainty functions are calculated in the respective approach. Next, we provide the practical application example of the proposed WASPAS-IVNS framework in search and rescue missions. 


\section{Experimental Evaluation of WASPAS-IVNS Framework}

In this research, search and rescue missions with time restrictions are considered. Robot operation time is bounded by a 20-min time interval, through which the autonomous robot must map the exploration environment and mark the detected OOI's on it. In this experiment, the OOIs are limited to human victims and dangerous objects.

\subsection{Search and Rescue Environment}

To assess the proposed WASPAS-IVNS framework in search and rescue missions, two indoor environments representing commercial-type and public-type buildings were considered. In the commercial-type building environments (e.g., retail shops), rooms and staff-only areas are relatively small and are commonly connected to each other by the central hall. This type of structure requires the robot to constantly backtrack to previous locations in order to visit new ones. Differently, public-type buildings, such as hospitals, are distinguished by wide open spaces and looping corridors, enabling the robot to observe more environment and detect dangerous OOIs in advance. Both of these environments are presented in Figure 2.

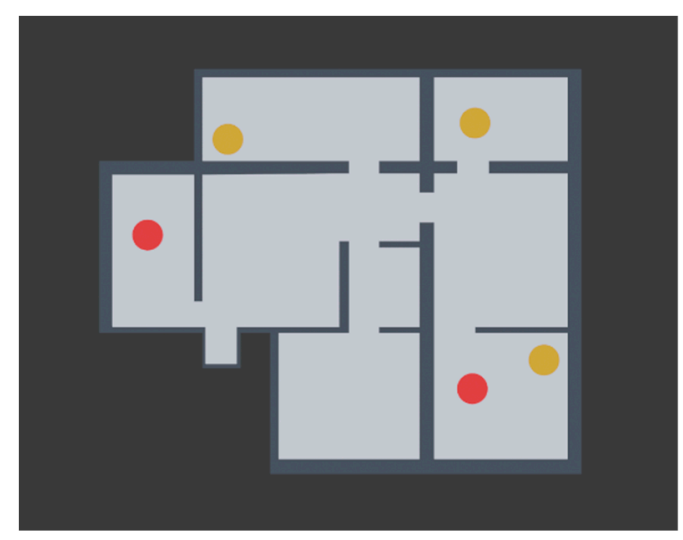

(a)

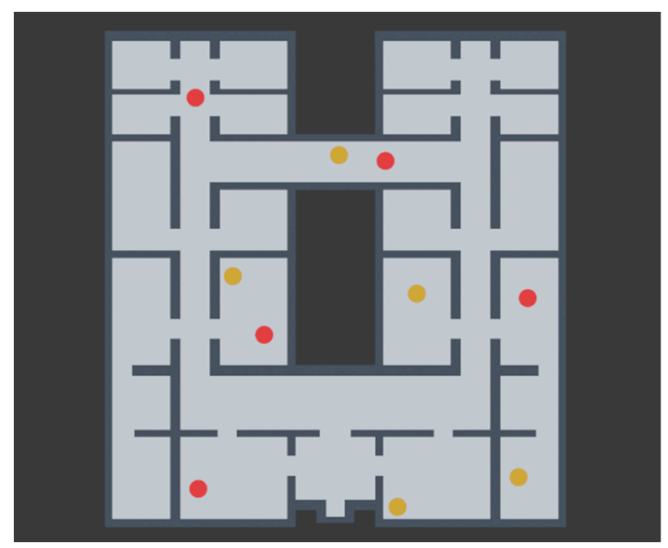

(b)

Figure 2. (a) The test environment representing commercial-type buildings; (b) The test environment representing public-type buildings.

Dangerous objects and victims are placed at random locations in both environments as presented in Figure 2. In this research, the red dots represent dangerous OOIs and yellow dots represent victims. The public-type building contains five victims and five dangerous objects that the robot should detect within the set time interval, and the commercial-type environment contains three victims, and two dangerous objects. Next, the example of candidate frontier evaluation by the proposed WASPAS-IVNS framework is presented.

\subsection{Frontier Evaluation by WASPS-IVNS Framework}

To highlight the practical application of the proposed WASPAS-IVNS framework, an example solution to one of the autonomous robot decision-making iterations is provided. The public-type building environment information, as mapped by the robot at the considered candidate frontier selection iteration, is provided in Figure 3. One victim and one dangerous object have already been found by the robot and marked by yellow and red dots, respectively. The robot is located at the position marked by a black dot, and the black line represents its previous movement trajectory. The available frontier regions are coloured in blue, and the green dots represent candidate frontier centre points $a_{i}(x, y)$ that robot decision-making module must evaluate. At this iteration, the robot has a total of seven candidate frontiers to choose from. 


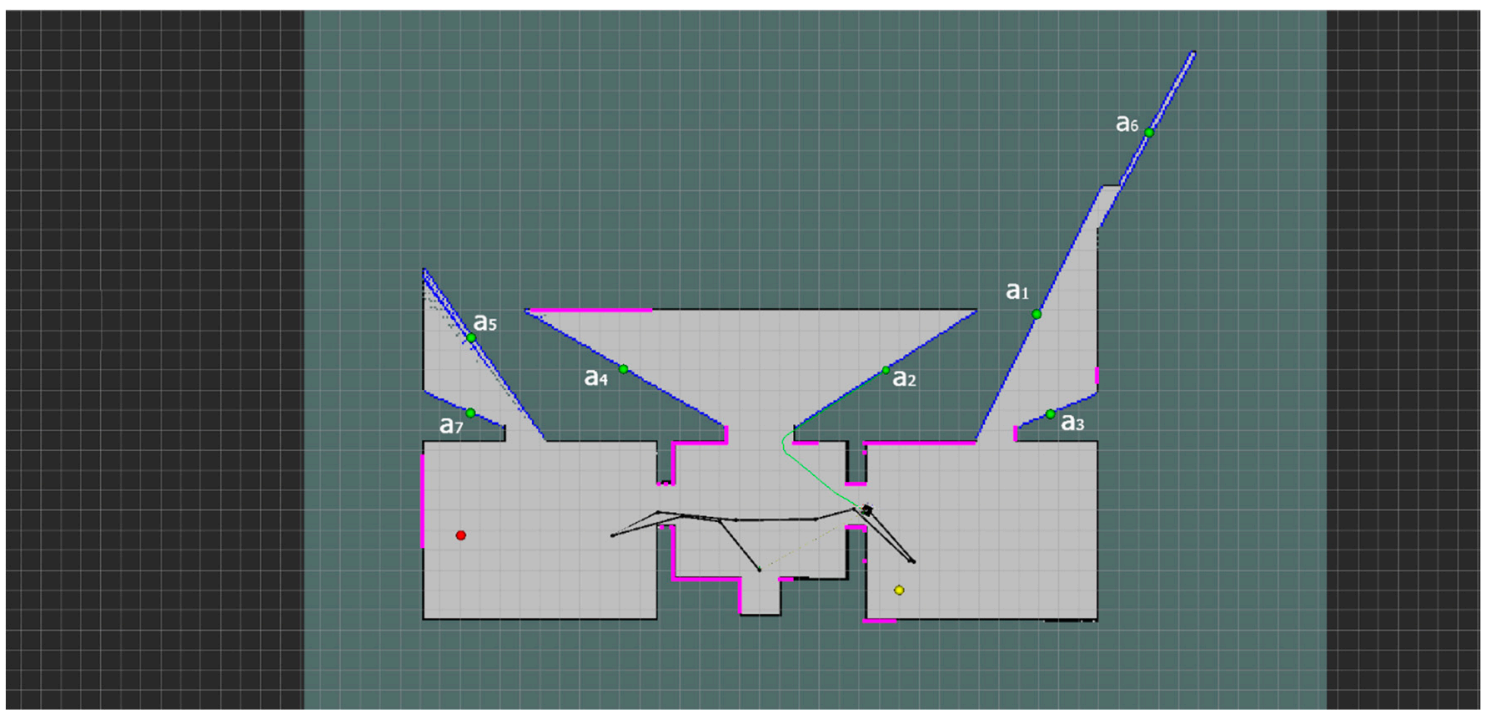

Figure 3. The public-type building environment mapped by the robot at the considered candidate frontier selection iteration.

First, criteria values are estimated for each candidate frontier location by applying the proposed methodology. In this iteration, no new OOIs were detected around candidate frontiers, hence $c_{3}$ and $c_{4}$ criteria values are null. Although these criteria do not influence the decision-making process in the considered iteration, it is highly recommended to change null values obtained in such situations to small positive number to stabilise the numerical computational procedure. The constructed decision matrix for the sample iteration is presented in Table 4.

Table 4. The initial decision matrix.

\begin{tabular}{ccccccc}
\hline & $c_{1}$ & $c_{2}$ & $c_{3}$ & $c_{4}$ & $c_{5}$ & $c_{6}$ \\
& Min & Max & Max & Min & Min & Min \\
\hline$w$ & 0.270 & 0.217 & 0.186 & 0.143 & 0.099 & 0.085 \\
$a_{1}$ & 18.89 & 12.7 & 0.10 & 0.10 & 25.2777 & 12.94 \\
$a_{2}$ & 11.84 & 9.1 & 0.10 & 0.10 & 37.5878 & 7.13 \\
$a_{3}$ & 16.54 & 4.0 & 0.10 & 0.10 & 39.0923 & 10.28 \\
$a_{4}$ & 12.15 & 10.3 & 0.10 & 0.10 & 33.0351 & 14.27 \\
$a_{5}$ & 18.54 & 16.4 & 0.10 & 0.10 & 60.8959 & 21.80 \\
$a_{6}$ & 29.33 & 15.5 & 0.10 & 0.10 & 31.5886 & 23.57 \\
$a_{7}$ & 16.47 & 4.0 & 0.10 & 0.10 & 63.4936 & 20.61 \\
\hline
\end{tabular}

Next, the neutrosophication step is performed. Results obtained by decision matrix element conversion to interval-valued neutrosophic numbers by WASPAS-IVNS are presented in Table 5 . 
Table 5. The decision matrix after the neutrosophication step by WASPAS-IVNS framework.

\begin{tabular}{ccccccc}
\hline & $c_{1}$ & $c_{2}$ & $c_{3}$ & $c_{4}$ & $c_{5}$ & $c_{6}$ \\
\hline \multirow{4}{*}{$a_{1}$} & {$[(0.223,0.802$,} & {$[(0.289,0.757$,} & {$[(0.139,0.672$,} & {$[(0.139,0.672$,} & {$[(0.079,0.859$,} & {$[(0.184,0.836$,} \\
& $0.752),(0.248$, & $0.707),(0.293$, & $0.622),(0.378$, & $0.622),(0.378$, & $0.819),(0.181$, & $0.786),(0.214$, \\
& $0.827,0.777)]$ & $0.761,0.711)]$ & $0.881,0.861)]$ & $0.881,0.861)]$ & $0.921,0.921)]$ & $0.858,0.816)]$ \\
\hline \multirow{2}{*}{$a_{2}$} & {$[(0.135,0.870$,} & {$[(0.206,0.839$,} & {$[(0.139,0.672$,} & {$[(0.139,0.672$,} & {$[(0.142,0.805$,} & {$[(0.094,0.887$,} \\
& $0.840),(0.160$, & $0.789),(0.211$, & $0.622),(0.378$, & $0.622),(0.378$, & $0.755),(0.245$, & $0.875),(0.125$, \\
& $0.882,0.865)]$ & $0.844,0.794)]$ & $0.881,0.861)]$ & $0.881,0.861)]$ & $0.879,0.858)]$ & $0.906,0.906)]$ \\
\hline \multirow{4}{*}{$a_{3}$} & {$[(0.194,0.831$,} & {$[(0.089,0.906$,} & {$[(0.139,0.672$,} & {$[(0.139,0.672$,} & {$[(0.150,0.798$,} & {$[(0.143,0.863$,} \\
& $0.781),(0.219$, & $0.906),(0.094$, & $0.622),(0.378$, & $0.622),(0.378$, & $0.748),(0.252$, & $0.826),(0.174$, \\
& $0.853,0.806)]$ & $0.911,0.911)]$ & $0.881,0.861)]$ & $0.881,0.861)]$ & $0.875,0.850)]$ & $0.879,0.857)]$ \\
\hline \multirow{3}{*}{$a_{4}$} & {$[(0.139,0.868$,} & {$[(0.234,0.812$,} & {$[(0.139,0.672$,} & {$[(0.139,0.672$,} & {$[(0.118,0.829$,} & {$[(0.204,0.815$,} \\
& $0.836),(0.164$, & $0.762),(0.238$, & $0.622),(0.378$, & $0.622),(0.378$, & $0.779),(0.221$, & $0.765),(0.235$, \\
& $0.881,0.861)]$ & $0.816,0.766)]$ & $0.881,0.861)]$ & $0.881,0.861)]$ & $0.892,0.882)]$ & $0.846,0.796)]$ \\
\hline \multirow{2}{*}{$a_{5}$} & {$[(0.219,0.806$,} & {$[(0.373,0.672$,} & {$[(0.139,0.672$,} & {$[(0.139,0.672$,} & {$[(0.262,0.685$,} & {$[(0.320,0.699$,} \\
& $0.756),(0.244$, & $0.622),(0.378$, & $0.622),(0.378$, & $0.622),(0.378$, & $0.635),(0.365$, & $0.649),(0.351$, \\
& $0.831,0.781)]$ & $0.677,0.627)]$ & $0.881,0.861)]$ & $0.881,0.861)]$ & $0.788,0.738)]$ & $0.730,0.680)]$ \\
\hline \multirow{2}{*}{$a_{6}$} & {$[(0.353,0.672$,} & {$[(0.353,0.693$,} & {$[(0.139,0.672$,} & {$[(0.139,0.672$,} & {$[(0.111,0.836$,} & {$[(0.347,0.672$,} \\
& $0.622),(0.378$, & $0.643),(0.357$, & $0.622),(0.378$, & $0.622),(0.378$, & $0.786),(0.214$, & $0.622),(0.378$, \\
& $0.697,0.647)]$ & $0.697,0.647)]$ & $0.881,0.861)]$ & $0.881,0.861)]$ & $0.894,0.889)]$ & $0.703,0.653)]$ \\
\hline \multirow{2}{*}{$a_{7}$} & {$[(0.193,0.832$,} & {$[(0.089,0.906$,} & {$[(0.139,0.672$,} & {$[(0.139,0.672$,} & {$[(0.275,0.672$,} & {$[(0.302,0.718$,} \\
& $0.782),(0.218$, & $0.906),(0.094$, & $0.622),(0.378$, & $0.622),(0.378$, & $0.622),(0.378$, & $0.668),(0.332$, \\
& $0.854,0.807)]$ & $0.911,0.911)]$ & $0.881,0.861)]$ & $0.881,0.861)]$ & $0.775,0.725)]$ & $0.748,0.698)]$ \\
\hline
\end{tabular}

The numerical results obtained by the first and second objectives of WASPAS-IVNS framework and the joint generalised criteria values are provided in Table 6 . The candidate frontier ranks are obtained by applying the score function and are provided in Table 7 . Considering the proposed environment exploration strategy, in this example iteration, frontier denoted by $a_{2}$ has the highest rank amongst candidate frontiers, and therefore is chosen as a next robot destination. Candidate frontier $a_{4}$ has similar initial criteria values and is ranked second. The main factor determining the next robot move, in this case, is $c_{6}$ criterion, which forces the robot decision-making module to prioritise the closer location.

Table 6. Numerical results obtained by WASPAS-IVNS framework.

\begin{tabular}{|c|c|c|c|}
\hline & $0.5 Q^{(1)}$ & $0.5 Q^{(2)}$ & $Q$ \\
\hline$a_{1}$ & $\begin{array}{l}{[(0.604,0.28,0.304)} \\
(0.696,0.362,0.396)]\end{array}$ & $\begin{array}{l}{[(0.137,0.814,0.798),} \\
(0.202,0.868,0.863)]\end{array}$ & $\begin{array}{c}{[(0.658,0.228,0.243),} \\
(0.757,0.314,0.342)]\end{array}$ \\
\hline$a_{2}$ & $\begin{array}{l}{[(0.616,0.268,0.281)} \\
(0.719,0.354,0.384)]\end{array}$ & $\begin{array}{l}{[(0.124,0.844,0.823)} \\
(0.177,0.887,0.876)]\end{array}$ & $\begin{array}{c}{[(0.664,0.226,0.231),} \\
(0.769,0.314,0.336)]\end{array}$ \\
\hline$a_{3}$ & $\begin{array}{l}{[(0.579,0.291,0.323),} \\
(0.677,0.378,0.421)]\end{array}$ & $\begin{array}{l}{[(0.079,0.882,0.886),} \\
(0.115,0.916,0.921)]\end{array}$ & $\begin{array}{c}{[(0.612,0.256,0.286),} \\
(0.714,0.347,0.388)]\end{array}$ \\
\hline$a_{4}$ & $\begin{array}{c}{[(0.613,0.271,0.288)} \\
(0.712,0.354,0.387)]\end{array}$ & $\begin{array}{l}{[(0.129,0.834,0.815)} \\
(0.185,0.879,0.871)]\end{array}$ & $\begin{array}{c}{[(0.663,0.226,0.234),} \\
(0.766,0.311,0.337)]\end{array}$ \\
\hline$a_{5}$ & $\begin{array}{l}{[(0.565,0.323,0.353),} \\
(0.647,0.405,0.435)]\end{array}$ & $\begin{array}{l}{[(0.136,0.805,0.801),} \\
(0.199,0.865,0.864)]\end{array}$ & $\begin{array}{c}{[(0.624,0.260,0.283),} \\
(0.717,0.350,0.376)]\end{array}$ \\
\hline$a_{6}$ & $\begin{array}{l}{[(0.551,0.352,0.372)} \\
(0.628,0.419,0.449)]\end{array}$ & $\begin{array}{l}{[(0.129,0.814,0.803)} \\
(0.197,0.871,0.871)]\end{array}$ & $\begin{array}{l}{[(0.609,0.287,0.298),} \\
(0.702,0.365,0.391)]\end{array}$ \\
\hline$a_{7}$ & $\begin{array}{l}{[(0.534,0.338,0.375)} \\
(0.625,0.426,0.466)]\end{array}$ & $\begin{array}{l}{[(0.072,0.890,0.895)} \\
(0.105,0.923,0.928)]\end{array}$ & $\begin{array}{c}{[(0.568,0.301,0.336),} \\
(0.664,0.393,0.432)]\end{array}$ \\
\hline
\end{tabular}


Table 7. Numerical results and candidate frontier rank obtained by applying score function.

\begin{tabular}{ccc}
\hline & $s(Q)$ & Rank \\
\hline$a_{1}$ & {$[2.002,2.286]$} & 3 \\
$a_{2}$ & {$[2.014,2.312]$} & 1 \\
$a_{3}$ & {$[1.877,2.172]$} & 5 \\
$a_{4}$ & {$[2.015,2.306]$} & 2 \\
$a_{5}$ & {$[1.898,2.174]$} & 4 \\
$a_{6}$ & {$[1.853,2.117]$} & 6 \\
$a_{7}$ & {$[1.743,2.027]$} & 7 \\
\hline
\end{tabular}

Compared to the WASPAS-SVNS method, the modelling of candidate frontier evaluation problem under interval-valued neutrosophic numbers enables the robot decision-making module to add into consideration the inaccuracies obtained by robot sensors and software component estimations. Unlike the WASPAS-SVNS method, the proposed WASPAS-IVNS framework provides additional tools for evaluating similar criteria values, and therefore enables the robot decision-making module to better estimate the final score values of the candidate frontiers. This framework difference is illustrated in Table 8, which presents candidate frontier score and rank results of the initial decision matrix (Table 4), obtained by applying the WASPAS-SVNS methodology described in [23]. In this example $a_{2}$ and $a_{4}$ frontier scores remain similar. However, due to a less effective approach, the robot is directed to $a_{4}$ frontier direction.

Table 8. The candidate frontier score results and rank obtained by applying WASPAS-SVNS methodology, presented in [23].

\begin{tabular}{ccc}
\hline & $s(Q)$ & Rank \\
\hline$a_{1}$ & 0.6655 & 3 \\
$a_{2}$ & 0.6708 & 2 \\
$a_{3}$ & 0.5982 & 5 \\
$a_{4}$ & 0.6719 & 1 \\
$a_{5}$ & 0.6171 & 4 \\
$a_{6}$ & 0.5812 & 6 \\
$a_{7}$ & 0.5193 & 7 \\
\hline
\end{tabular}

\subsection{Search and Rescue Mission Simulation Results}

Next, we discuss the autonomous search and rescue mission results, obtained by the ten test runs in commercial-type and public-type building environments. The same set of already introduced rules were applied in each test. The obtained environment information in square meters, received penalty points, and a number of detected dangerous objects and victims are presented in Table 9. 
Table 9. Assessment results obtained by the WASPAS-IVNS framework in commercial and public-type buildings.

\begin{tabular}{|c|c|c|c|c|c|c|c|c|c|c|c|c|}
\hline & & \multicolumn{10}{|c|}{ Test Run } & \multirow[b]{2}{*}{ Average Value } \\
\hline & & 1 & 2 & 3 & 4 & 5 & 6 & 7 & 8 & 9 & 10 & \\
\hline \multirow{4}{*}{$\begin{array}{l}\text { Public building } \\
\text { environment }\end{array}$} & Environment information & 811.2 & 861.7 & 796.4 & 895.9 & 706.2 & 783.0 & 877.0 & 752.4 & 771.5 & 873.4 & 812.9 \\
\hline & Received penalty points & 2.36 & 0.86 & 0.00 & 4.13 & 0.00 & 0.79 & 1.39 & 0.90 & 0.00 & 0.00 & 1.04 \\
\hline & Detected dangerous objects & 2 & 3 & 2 & 3 & 2 & 2 & 3 & 2 & 2 & 2 & 2.3 \\
\hline & Detected victims & 2 & 1 & 2 & 2 & 2 & 3 & 2 & 2 & 3 & 3 & 2.2 \\
\hline \multirow{4}{*}{$\begin{array}{c}\text { Commercial building } \\
\text { environment }\end{array}$} & Environment information & 494.7 & 495.0 & 494.9 & 494.5 & 494.0 & 495.5 & 460.8 & 494.6 & 494.2 & 494.7 & 491.3 \\
\hline & Received penalty points & 4.27 & 1.79 & 5.12 & 7.79 & 1.87 & 4.32 & 10.45 & 11.22 & 4.50 & 2.94 & 5.43 \\
\hline & Detected dangerous objects & 2 & 2 & 2 & 2 & 2 & 2 & 2 & 2 & 2 & 2 & 2 \\
\hline & Detected victims & 3 & 3 & 3 & 3 & 3 & 3 & 3 & 3 & 3 & 3 & 3 \\
\hline
\end{tabular}


By comparing robot behaviour and the results obtained between the commercial-type and public-type building environments, several observations can be made. The results of the autonomous robot exploration obtained in the small commercial-type building environments are presented in Figure 4.

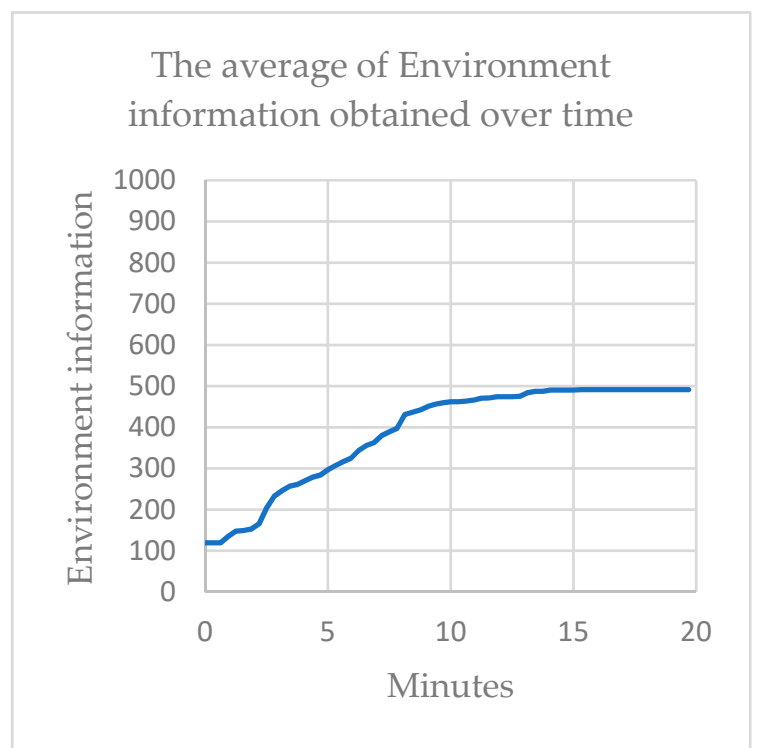

(a)

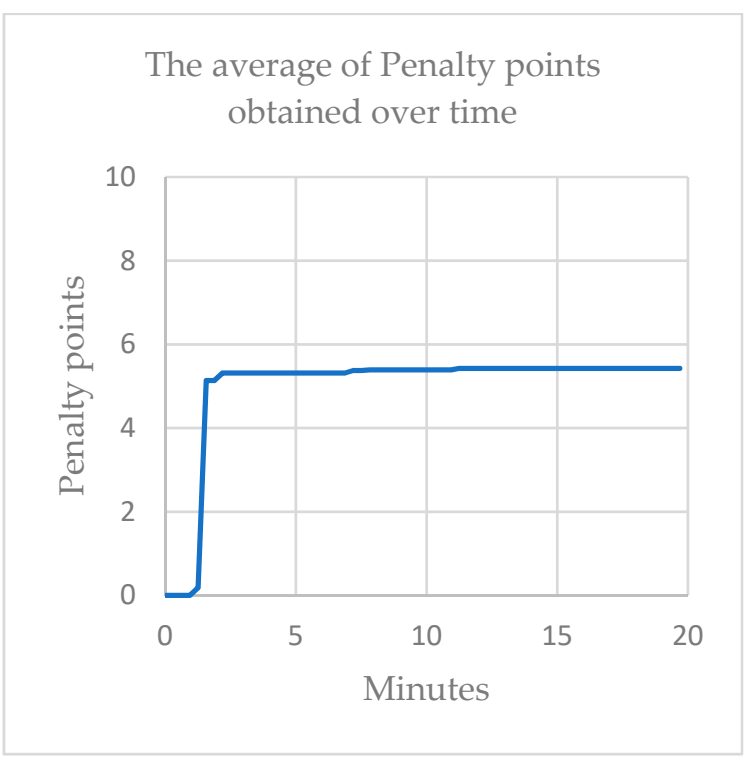

(b)

Figure 4. (a) The average of environment information obtained during ten 20-min-long autonomous search and rescue missions in commercial-type building environment; (b) The average penalty points obtained by the robot during the same test runs.

In this environment, the autonomous robot was able to map the whole exploration space, totalling at an average of 491.3 square meters, and detect all OOIs before the given time limit. However, the robot also received heavy penalties, averaging at 5.43 penalty points. This can be explained by addressing the proposed environment exploration strategy, namely the distribution of criteria weights. The proposed strategy prioritises exploration before robot safety, and therefore, ensures that nearby locations would be visited first. As can be seen in Figure 4 and from the robot movement trajectory in one of the test runs, presented in Figure 5, robot decision-making module first directs the robot to visit the room on the left. However, the dangerous obstacle is not seen from the robot starting location, and this criterion does not participate in the decision-making process. Therefore, the robot drives into a room and receives a penalty at early exploration stages.

However, a different behaviour can be observed near the end of the search and rescue mission. When the robot decision-making module has to choose between the room at the top-right and the room at the bottom-left corner of the map, the robot is first directed to visit the room at the top. In this situation, the robot can see the victim in a nearby room, and a dangerous object, located at the bottom of the map. The proposed decision-making strategy prioritises the minimisation of the expected damage to the robot and to make contact with the victim. Hence, the last room is visited only when there are no more options left. Here, by evading the dangerous OOI blocking its way, the robot detects the hidden victim. 


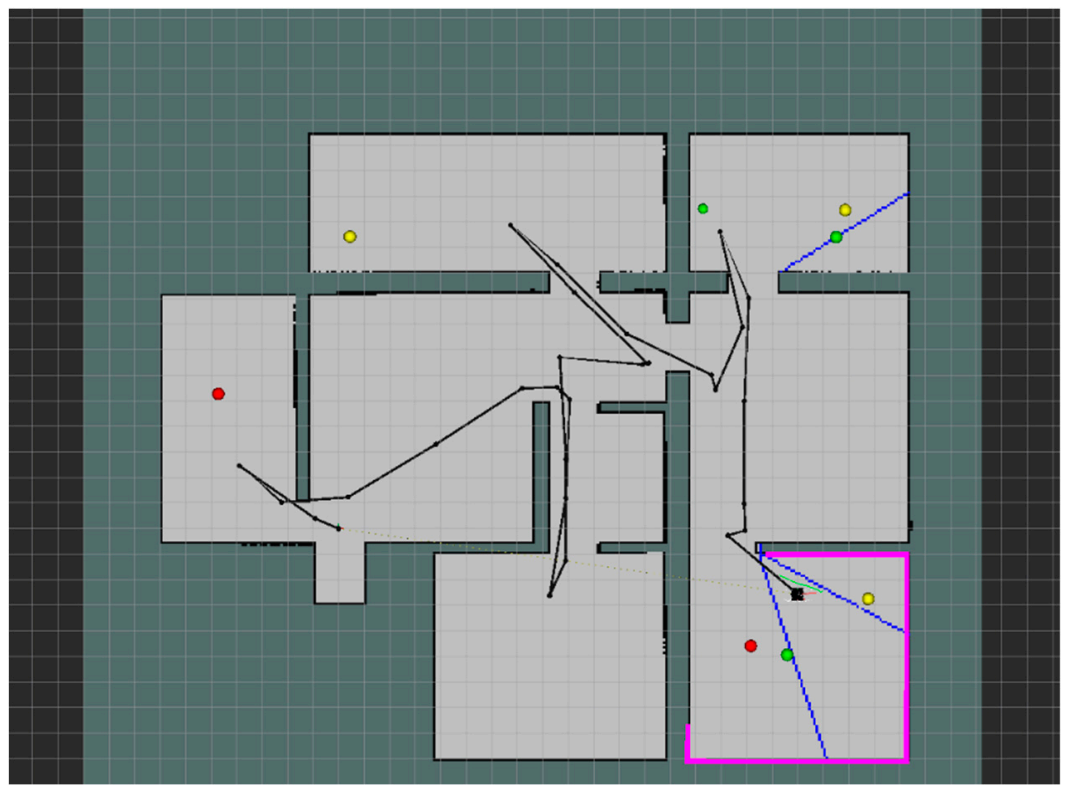

Figure 5. Autonomous robot movement trajectory in commercial building environment.

The results of autonomous robot exploration in a public-type building environment are presented in Figure 6.

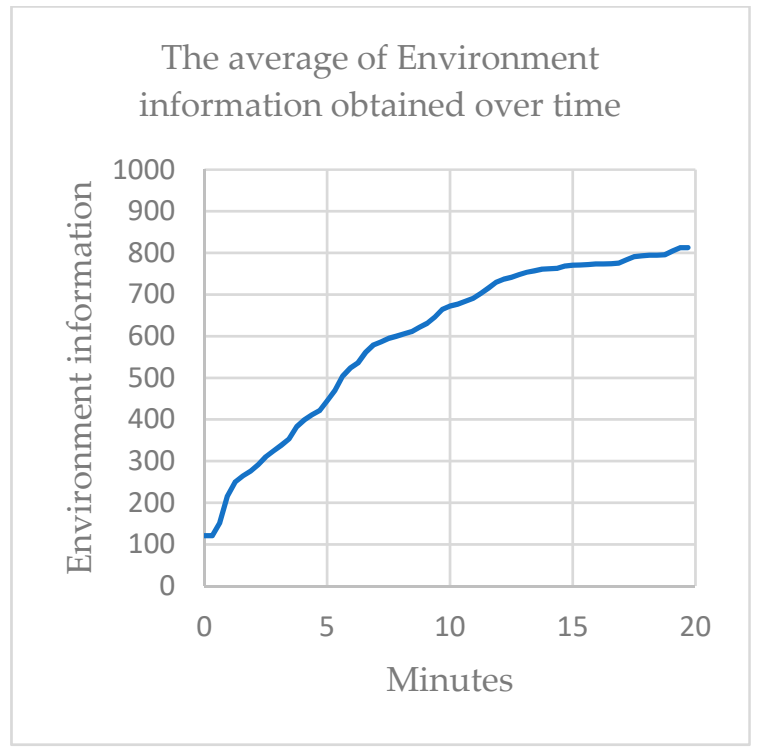

(a)

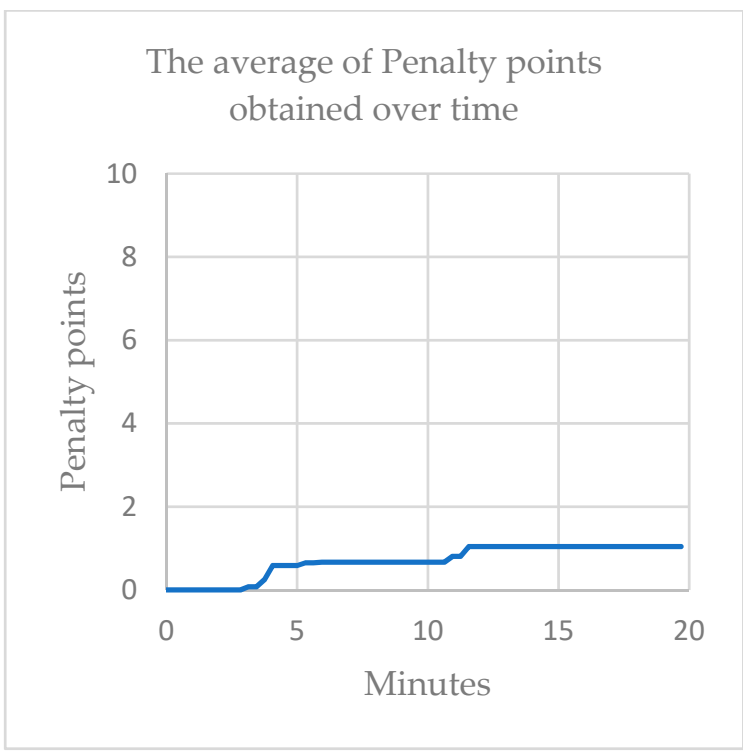

(b)

Figure 6. (a) The average of environment information obtained during ten 20-min-long autonomous search and rescue missions in public-type building environment; (b) The average penalty points obtained by the robot during the same test runs.

Differently from the commercial-type building environments, in a public-type building environment, the robot was not able to complete an exhaustive environment exploration, due to the set time restrictions. These results are to be expected when applying the proposed environment exploration strategy, especially when considering the $c_{1}$ criterion, denoting the distance from the candidate frontier location to the robot control centre. The criterion is minimised, to ensure that the robot will be able to transfer the obtained information after reaching the candidate frontier. Therefore, at the start of the search and rescue mission, the robot spends a lot of time analysing nearby locations, as presented by the robot movement trajectory in one of the test runs, depicted in Figure 7. 


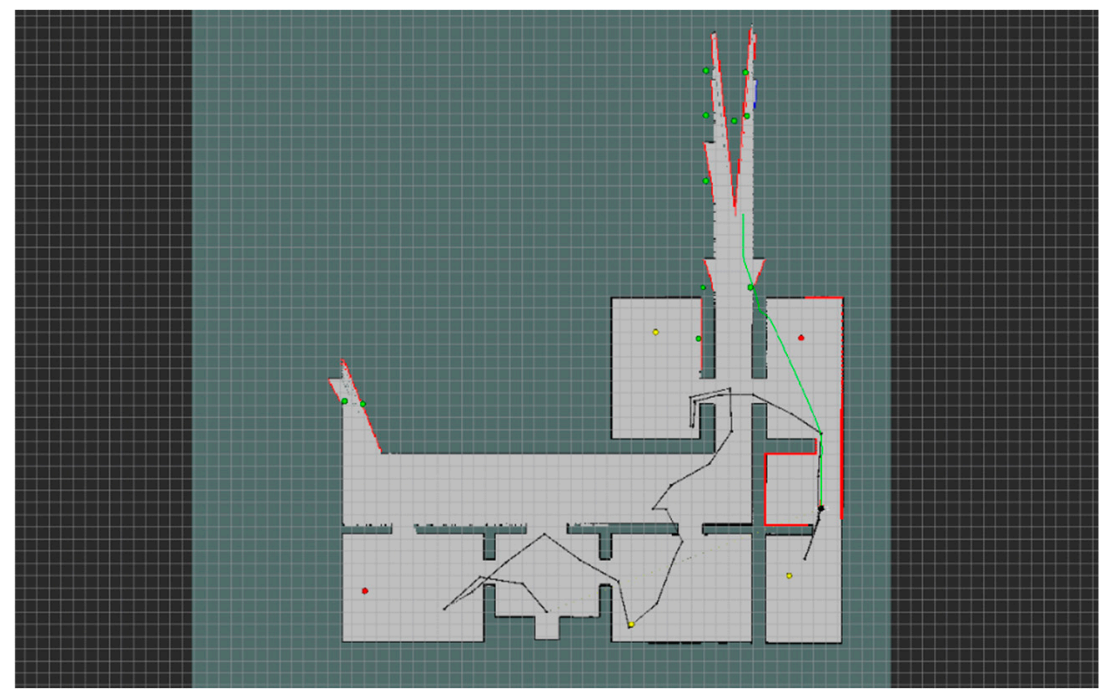

Figure 7. Autonomous robot movement trajectory in public building environment.

On average, the robot managed to map 812.9 square meters of environmental information and detect 2.3 dangerous objects and 2.2 victims. However, the robot also received fewer penalty points, averaging at 1.04. The small number of received penalty points can also be explained not only by the integration of the proposed criteria, but also by analysing the physical structure of the test environment. In this case, wide-open spaces enable the robot to detect dangerous objects in advance and to make the decisions accordingly.

\section{Conclusions}

Autonomous robot applications in search and rescue missions requires the robot decision-making module to be capable of making effective decisions in unknown environments by taking into consideration a set of mission-related criteria. However, the quality of robot-made decisions can be affected by the small errors in the initial data (e.g., imprecise environment map representation or sensor readings). Hence, in this research, a new frontier evaluation strategy is proposed for modelling search and rescue missions by introducing a new set of criteria that addresses technical, environmental, social, and economic factors of SAR missions. The robot-applied candidate frontier evaluation process is explicitly controlled by the proposed interval-valued neutrosophic WASPAS framework, namely, WASPAS-IVNS. This method is introduced to improve the decision-making process by addressing small measurement errors, obtained due to imperfect sensor readings and imprecise robot movements.

The experimental evaluation results show that our proposed method is effective in search and rescue scenarios and can be applied to solve complex real-time tasks. By addressing the estimated measurement errors, the proposed decision-making framework provides additional reliability when comparing candidate frontiers with similar initial criteria values, as presented in Section 4.2. In relatively small commercial-type buildings, the robot can conduct an exhaustive search and create a complete map of the environment before reaching the given time limit of $20 \mathrm{~min}$. However, bigger, public-type building environments are more problematic in a sense that robot has to cover more area with same time restrictions. Therefore, the proposed criteria list should be adjusted accordingly. For example, the $c_{1}$ criterion should be maximised to direct the robot to further located frontiers.

The conducted experiments also show that the biggest threats to the robot in such environments are unknown damage sources. The proposed criteria set is only effective when the robot can detect and evaluate all task-related information. If the robot has no information about the objects located around the corners, the decision-making module has no method to estimate the possible danger or benefit of finding a victim and makes the decision, based only on $c_{1}, c_{2}, c_{5}, c_{6}$ criteria. 
For possible future work, the authors will consider addressing this problem by introducing additional robot movement rules that would stop the robot and force it to re-evaluate the decision as soon as it drives through the doors or obtains new environment information. The authors also consider expanding the proposed criteria list by conducting a more in-depth interview of stakeholders to identify and address other common search and rescue requirements.

Author Contributions: Conceptualization, R.S. and R.B.; methodology, R.S. and R.B.; software, R.S.; validation, R.S. and R.B.; formal analysis, R.S. and R.B.; investigation, R.S.; resources, R.S.; data curation, R.S.; writing-original draft preparation, R.S.; writing - review and editing, R.S. and R.B.; visualization, R.S.; supervision, R.B.; project administration, R.S. and R.B. All authors have read and agreed to the published version of the manuscript.

Funding: This research received no external funding.

Conflicts of Interest: The authors declare no conflict of interest.

\section{References}

1. Bloom, D.E.; McKenna, M.J.; Prettner, K. Global employment and decent jobs, 2010-2030: The forces of demography and automation. Int. Soc. Secur. Rev. 2019, 72, 43-78. [CrossRef]

2. Litman, T. Autonomous vehicle implementation predictions. In Implications for Transport Planning 2017; Victoria Transport Policy Institute: Victoria, BC, Canada, 2017.

3. Čaić, M.; Mahr, D.; Oderkerken-Schröder, G. Value of social robots in services: Social cognition perspective. J. Serv. Mark. 2019, 33, 463-478. [CrossRef]

4. Walker, N.; Jiang, Y.; Cakmak, M.; Stone, P. Desiderata for Planning Systems in General-Purpose Service Robots. arXiv 2019, arXiv:1907.02300.

5. Amigoni, F.; Schiaffonati, V. Ethics for Robots as Experimental Technologies, Pairing Anticipation with Exploration to Evaluate the Social Impact of Robotics. IEEE Robot. Autom. Mag. 2018, 25, 30-36. [CrossRef]

6. Sutter, B.; Lelevé, A.; Pham, M.T.; Gouin, O.; Jupille, N.; Kuhn, M.; Lulé, P.; Michaud, P.; Rémy, P. A Semi-Autonomous Mobile Robot for Bridge Inspection. Autom. Constr. 2018, 91, 111-119. [CrossRef]

7. Menendez, E.; Victores, J.G.; Montero, R.; Martínez, S.; Balaguer, C. Tunnel Structural Inspection and Assessment Using an Autonomous Robotic System. Autom. Constr. 2018, 87, 117-126. [CrossRef]

8. Sheh, R.; Schwertfeger, S.; Visser, A. 16 Years of RoboCup Rescue. Künstl. Intell. 2016, 30, 267-277. [CrossRef]

9. Cubber, G.D.; Doroftei, D.; Rudin, K.; Berns, K.; Matos, A.; Serrano, D.; Sanchez, J.; Govindaraj, S.; Bedkowski, J.; Roda, R.; et al. Introduction to the use of robotic tools for search and rescue. In Search and Rescue Robotics; IntechOpen: London, UK, 2017; pp. 1-17.

10. Tsitsimpelis, I.; Taylor, C.J.; Lenox, B.; Joyce, M.J. A review of ground-based robotic systems for the characterization of nuclear environments. Prog. Nucl. Energy 2019, 111, 109-124. [CrossRef]

11. Huang, X.; Arvin, F.; West, C.; Watson, S.; Lennox, B. Exploration in Extreme Environments with Swarm Robotic System. In Proceedings of the 2019 IEEE International Conference on Mechatronics (ICM), Ilmenau, Germany, 18-20 March 2019; Volume 1, pp. 193-198.

12. Axelrod, B.; Huang, W.H. Autonomous Door Opening and Traversal. In Proceedings of the 2015 IEEE International Conference on Technologies for Practical Robot Applications (TePRA), Woburn, MA, USA, 11-12 May 2015; pp. 1799-1806.

13. Mac, T.T.; Copot, C.; Ionescu, C.M. Design and Implementation of a Real-Time Autonomous Navigation System Applied to Lego Robots. In Proceedings of the 3rd IFAC Conference on Advances in ProportionalIntegral-Derivative Control, Ghent, Belgium, 9-11 May 2018.

14. Harbers, M.; de Greeff, J.; Kruijff-Korbayová, I.; Neerincx, M.A.; Hindriks, K.V. Exploring the ethical landscape of robot-assisted search and rescue. In A World with Robots; Springer: Cham, Switzerland, 2017; pp. 93-107.

15. Julia, M.; Gil, A.; Reinoso, O. A comparison of path planning strategies for autonomous exploration and mapping of unknown environments. Auton. Robot. 2012, 33, 427-444. [CrossRef]

16. Bayat, B.; Crasta, N.; Crespi, A.; Pascoal, A.M.; Ijspeert, A. Environmental Monitoring using Autonomous Vehicles: A Survey of Recent Searching Techniques. Curr. Opin. Biotechnol. 2017, 45, 76-84. [CrossRef] 
17. Zhu, F.; Elliot, D.S.; Yang, Z.; Zheng, H. Learned and Controlled Autonomous Robotic Exploration in an Extreme, Unknown Environment. In Proceedings of the 2019 IEEE Aerospace Conference, Big Sky, MT, USA, 2-9 March 2019; pp. 1-10.

18. Schuster, M.J.; Brunner, S.G.; Bussmann, K.; Büttner, S.; Dömel, A.; Hellerer, M.; Lehner, P.; Porges, O.; Reill, J.; Riedel, S.; et al. Towards Autonomous Planetary Exploration. J. Intell. Robot. Syst. 2019, 93, 461-494. [CrossRef]

19. Arm, P.; Zenkl, R.; Sun, B.; Hutter, M.; Kolvenbach, H.; Dietsche, A.; Schaufelberger, D.; Stolz, B.; Hampp, E.; Barton, P.; et al. SpaceBok: A Dynamic Legged Robot for Space Exploration. In Proceedings of the International Conference on Robotics and Automation (ICRA 2019), Montreal, QC, Canada, 20-24 May 2019.

20. Yamauchi, B. A frontier-based approach for autonomous exploration. In Proceedings of the 1997 IEEE International Symposium on Computational Intelligence in Robotics and Automation CIRA'97. Towards New Computational Principles for Robotics and Automation, Monterey, CA, USA, 10-11 July 1997; pp. 146-151.

21. Selin, M.; Tiger, M.; Duberg, D.; Heintz, F.; Jensfelt, P. Efficient Autonomous Exploration Planning of Large-Scale 3-D Environments. IEEE Robot. Autom. Lett. 2019, 4, 1699-1706. [CrossRef]

22. Fang, B.; Ding, J.; Wang, Z. Autonomous robotic exploration based on frontier optimization and multistep path planning. IEEE Access 2019, 7, 46104-46113. [CrossRef]

23. Bausys, R.; Cavallaro, F.; Semenas, R. Application of Sustainability Principles for Harsh Environment Exploration by Autonomous Robot. Sustainability 2019, 11, 2518. [CrossRef]

24. Aruldoss, M.; Lakshmi, T.M.; Venkatesan, V.P. A Survey on Multi Criteria Decision Making Methods and Its Applications. Am. J. Inf. Syst. 2013, 1, 31-43.

25. Kazimieras, Z.E.; Romualdas, B.; Dragisa, S.; Marija, M. Selection of lead-zinc flotation circuit design by applying WASPAS method with single-valued neutrosophic set. In Acta Montanistica Slovaca; Technical University of Košice: Košice, Slovakia, 2016; Volume 21, pp. 85-92.

26. Zavadskas, E.K.; Bausys, R.; Lazauskas, M. Sustainable assessment of alternative sites for the construction of a waste incineration plant by applying WASPAS method with single-valued neutrosophic set. Sustainability 2015, 7, 15923-15936. [CrossRef]

27. Juodagalvienè, B.; Turskis, Z.; Šaparauskas, J.; Endriukaitytè, A. Integrated multi-criteria evaluation of house's plan shape based on the EDAS and SWARA methods. Eng. Struct. Technol. 2017, 9, 117-125. [CrossRef]

28. Stojić, G.; Stević, Ž.; Antuchevičienè, J.; Pamučar, D.; Vasiljević, M. A novel rough WASPAS approach for supplier selection in a company manufacturing PVC carpentry products. Information 2018, 9, 121. [CrossRef]

29. Zavadskas, E.K.; Bausys, R.; Mazonaviciute, I. Safety evaluation methodology of urban public parks by multi-criteria decision making. Landsc. Urban Plan. 2019, 189, 372-381. [CrossRef]

30. Diaz-Balteiro, L.; González-Pachón, J.; Romero, C. Measuring systems sustainability with multi-criteria methods: A critical review. Eur. J. Oper. Res. 2017, 258, 607-616. [CrossRef]

31. Kumar, A.; Sah, B.; Singh, A.R.; Deng, Y.; He, X.; Kumar, P.; Bansal, R.C. A review of multi criteria decision making (MCDM) towards sustainable renewable energy development. Renew. Sustain. Energy Rev. 2017, 69, 596-609. [CrossRef]

32. Zavadskas, E.K.; Nunić, Z.; Stjepanović, Ž.; Prentkovskis, O. A novel rough range of value method (R-ROV) for selecting automatically guided vehicles (AGVs). Stud. Inform. Control 2018, 27, 385-394. [CrossRef]

33. Ghorabaee, M.K. Developing an MCDM Method for Robot Selection with Interval Type-2 Fuzzy Sets. Rob. Comput. Integr. Manuf. 2016, 37, 221-232. [CrossRef]

34. Chatterjee, P.; Athawale, V.M.; Chakraborty, S. Selection of industrial robots using compromise ranking and outranking methods. Robot. Comput. Integr. Manuf. 2010, 26, 483-489. [CrossRef]

35. Amigoni, F.; Basilico, N. A Decision-Theoretic Framework to Select Effective Observation Locations in Robotic Search and Rescue Scenarios. In Proceedings of the IEEE International Conference on Robotics and Automation. Workshop on "Search and Pursuit/Evasion in Physical World: Efficiency, Scalability, and Guarantees", Anchorage, AK, USA, 3 May 2010.

36. Taillandier, P.; Stinckwich, S. Using PROMETHEE multi-criteria decision making method to define new exploration strategies for rescue robots. In Proceedings of the IEEE International Symposium on Safety, Security, and Rescue Robotics, Kyoto, Japan, 1-5 November 2011; pp. 321-326.

37. ROS.org|Ros robots. Pioneer 3-AT. Medium-Sized General-Purpose Skid-Steer Mobile Robot Platform. Available online: https://robots.ros.org/pioneer-3-at/ (accessed on 20 November 2019). 
38. Jiang, S. A Study of Initiative Decision-Making in Distributed Human-Robot Teams. In Proceedings of the 2019 Third IEEE International Conference on Robotic Computing (IRC), Naples, Italy, 25-27 February 2019; pp. 349-356.

39. ROS. Available online: https://www.ros.org/ (accessed on 20 November 2019).

40. Gazebo. Anon. 2018. Available online: http://gazebosim.org/ (accessed on 20 November 2019).

41. ROS.org|Gmapping. Available online: http://wiki.ros.org/gmapping (accessed on 22 November 2019).

42. Keršulienė, V.; Zavadskas, E.K.; Turskis, Z. Selection of rational dispute resolution method by applying new step-wise weight assessment ratio analysis (Swara). JBEM 2010, 11, 243-258. [CrossRef]

43. Zavadskas, E.K.; Turskis, Z.; Antucheviciene, J.; Zakarevicius, A. Optimization of weighted aggregated sum product assessment. Electron. Electr. Eng. = Elektron. Ir Elektrotechnika 2012, 122, 3-6. [CrossRef]

44. Mardani, A.; Nilashi, M.; Zakuan, N.; Loganathan, N.; Soheilirad, S.; Saman, M.Z.M.; Ibrahim, O. A systematic review and meta-Analysis of SWARA and WASPAS methods: Theory and applications with recent fuzzy developments. Appl. Soft Comput. 2017, 57, 265-292. [CrossRef]

45. Smarandache, F. A unifying field in logics. In Neutrosophy: Neutrosophic Probability, Set and Logic; American Research Press: Rehoboth, DE, USA, 1999.

46. Zhang, H.Y.; Wang, J.G.; Chen, X.H. Interval Neutrosophic Sets and Their Application in Multicriteria Decision Making Problems. Sci. World J. 2014. [CrossRef]

(C) 2020 by the authors. Licensee MDPI, Basel, Switzerland. This article is an open access article distributed under the terms and conditions of the Creative Commons Attribution (CC BY) license (http://creativecommons.org/licenses/by/4.0/). 